Article

\title{
Optimum Subsidy to Promote Electric Boiler Investment to Accommodate Wind Power
}

\author{
Da Liu ${ }^{1, *}$, Shou-Kai Wang ${ }^{1}$, Jin-Chen Liu ${ }^{1}$, Han Huang ${ }^{1}$, Xing-Ping Zhang ${ }^{1}$, Yi Feng ${ }^{2}$ and \\ Wei-Jun Wang ${ }^{1}$ \\ 1 Beijing Key Laboratory of New Energy and Low-Carbon Development, \\ North China Electric Power University, Beijing 102206, China; wsk425670241@ncepu.edu.cn (S.-K.W.); \\ 1111570113@ncepu.edu.cn (J.-C.L.); 50601651@ncepu.edu.cn (H.H.); zxp@ncepu.edu.cn (X.-P.Z.); \\ wwjhd@ncepu.edu.cn (W.-J.W.) \\ 2 State Grid Electric Vehicle Service Co., Beijing 100053, China; fengyi@evs.sgcc.com.cn \\ * Correspondence: liuda@ncepu.edu.cn; Tel.: +86-10-6177-3138
}

Academic Editor: Tomonobu Senjyu

Received: 21 April 2017; Accepted: 19 May 2017; Published: 25 May 2017

\begin{abstract}
The increasing development of combined heat and power (CHP) plants is exacerbating the wind power curtailment problem in regional power grids during the winter heating season. Electric boilers (EBs) were proposed to be employed within CHP plants to relieve this problem. However, CHP plants usually have no incentive for investing in EBs. Therefore, CHP plants must be incentivized to make such investments through appropriate compensation from beneficiaries, i.e., government and wind farms, although this has not previously been discussed. We propose a game theory model to simulate the impact of government subsidies on EB investment. We analyzed the utilization of the involved parties with the marginal cost and average cost and applied game theory to simulate the investment decisions. Then, an approximate enumeration technique was developed to identify the optimum government subsidy. An actual case of a regional power grid in northern China was investigated to validate the proposed method. A minimum government subsidy to maximize total social benefit was calculated; this subsidy can incentivize wind farms and CHP plants to invest in and use EBs.
\end{abstract}

Keywords: wind power accommodation; combined heat and power (CHP) plants; electric boilers (EBs); government subsidy; game analysis model

\section{Introduction}

Worldwide, wind power has become one of the most competitive renewable energies for mitigating energy and environmental problems despite its random and intermittent characteristics [1]. The rapid expansion of wind power over the past several years has evoked significant concern about the safety of its integration with the grid [2,3]. The problem is exacerbated in regional power grids, where combined heat and power (CHP) plants provide the majority of the electric power supply during the heating season. The development of CHP plants is encouraged through fixed feed-in tariffs and priority scheduling. Thence, the peak regulation capability of the power grid is abated by the CHP units' inflexible response during the heating season [4,5]. Massive wind power curtailment occurs and slows the worldwide effort to increase sustainable energy development [6]. Thus, an efficient method for mitigating wind power curtailment is urgently needed $[7,8]$.

The majority of previous studies focused on energy storage technologies, demand response, interregional accommodation, and electric boilers (EBs). Energy storage is considered to be an effective method, and its technology has significant potential for improvement [9-11]. Demand response adjusts 
the load demand to match the variable wind power $[12,13]$, whereas interregional accommodation is proposed to accommodate wind energy located far from the load center [14,15].

The use of EBs within CHP plants is suggested to increase the plant's power supply flexibility and improve the grid's capacity to accommodate wind power [16-18]. The electricity consumed by EBs reserves more grid capacity to accommodate wind power [16]. Employing EBs to accommodate wind power has been shown to be feasible using value analysis [19,20], scheme design [21,22], and optimal capacity allocation [16].

Investing in EBs will accommodate a larger amount of wind power, increase clean energy generation, and create additional wind farm profits. Therefore, both the government and wind farms are motivated to increase investments in EBs. From the perspective of social cost minimization, the installation of EBs in CHP plants via the cooperation of CHP plants is crucial. However, increasing the use of EBs decreases the profits of CHP plants by reducing their power output. CHP plants will reject the use of EBs unless sufficient compensation is provided by the government and wind farms.

Benefit allocation is important for projects in which multiple investors compete for advantageous positions and every investor strives to maximize profits with an optimum decision [23]. To address the conflicts that arise among the involved parties, a well-designed government subsidy scheme can reduce these conflicts and promote the implementation of these projects.

Subsidy policies have been extensively implemented to promote new energy development [24,25]. The government will face a trade-off in this type of project: achieving maximum social benefit subsidies while minimizing the total subsidy. However, no studies have addressed the impact of government subsidies on EB investments. In this paper, we aim to build a model to promote wind power accommodation with EB investment to maximize social benefits while minimizing the government subsidy.

The remainder of this paper consists of three sections: Section 2 discusses the background knowledge for employing EBs in CHP plants and the game model between wind farms and CHP plants for EB investment. Section 3 presents a case study of the Beijing-Tianjin-Hebei (BTH) power grid located in northern China to illustrate the proposed model. Section 4 presents the conclusion

\section{Principles and Method}

\subsection{Background for Employing EBs in CHP Plants}

We assume that EBs are installed in CHP plants and only run when wind power curtailment occurs [16]. In addition, all electricity consumed by the EBs is assumed to originate from the CHP units. With the supplementary heat generated by the EBs, the CHP units have additional capacity to respond to the regulation of the grid. The increase in the wind power accommodation of this system is equal to the decrease in the power supply of the CHP plant. Figure 1 shows the change in the electricity and heat production of the CHP plants after EBs are employed.

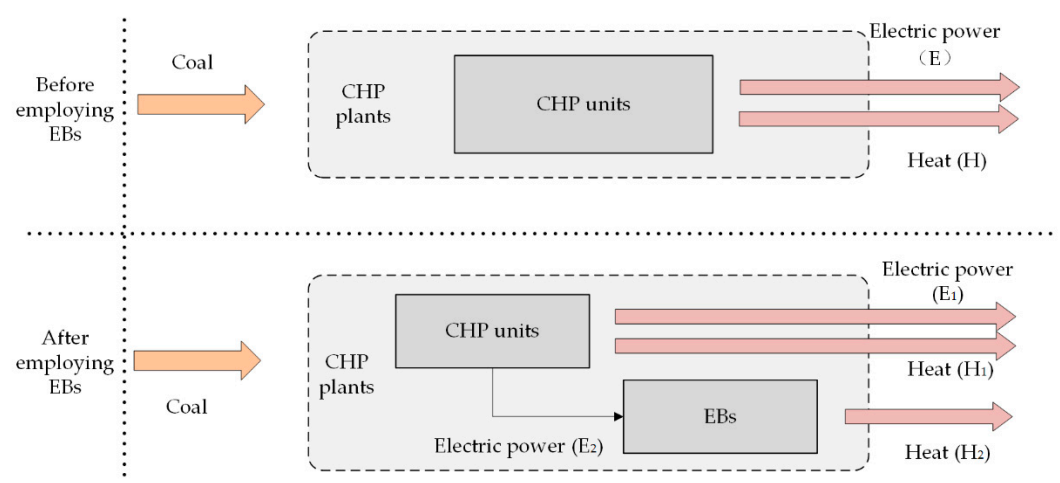

Figure 1. Change in the production of the CHP plant after employing EBs. 
In the figure, $E$ and $H$ are the electric power supply $(\mathrm{kW})$ and heat supply $(\mathrm{GJ} / \mathrm{h})$ from the CHP plants before employing EBs, respectively; $E_{1}$ and $H_{1}$ are the electric power supply and heat supply from the CHP units after employing EBs, respectively; and $E_{2}$ and $H_{2}$ are the power consumption of the EBs and the heat supply of the EBs, respectively.

Before employing the EBs, the CHP units generate electric power $(E)$ and heat $(H)$ by burning coal; after employing the EBs, the CHP units generate electric power $\left(E_{1}+E_{2}\right)$ and heat $\left(H_{1}\right)$, whereas the EBs consume electric power $\left(E_{2}\right)$ and provide heat $\left(H_{2}\right)$. By employing EBs, the CHP plants provide electric power $\left(E_{1}\right)$ and heat $\left(H_{1}+H_{2}\right)$.

We assume that the use of EBs does not change the total heat supply of the CHP plants as the EBs provide the exact amount of heat that was originally provided by the CHP units, as shown in Formula (1). For simplicity, the average thermoelectric ratio of all CHP units is assumed to be the same constant value before and after EBs are employed [16], as shown in Formula (2).

$$
\begin{aligned}
H & =H_{1}+H_{2} \\
\frac{H}{E} & =\frac{H_{1}}{E_{1}+E_{2}}
\end{aligned}
$$

After employing EBs, the gap in the electricity supply from the CHP plants, which is represented by $\left(E-E_{1}\right)$, is provided by wind power; this value is the wind power accommodation that would otherwise be curtailed. The effectiveness of employing EBs for wind power accommodation is calculated as

$$
\theta=\frac{E-E_{1}}{E_{2}}
$$

Thus, the quantity of wind power accommodation after employing EBs is

$$
\begin{gathered}
Q=\Delta t \times \sum_{t=1}^{T}\left(P_{W_{t}} \times v+P_{B} \times \theta \times(1-V)\right) \\
v= \begin{cases}0, & P_{W_{t}} \geq P_{B} \times \theta \\
1, & P_{W_{t}}<P_{B} \times \theta\end{cases}
\end{gathered}
$$

\subsection{Game Analysis Model}

\subsubsection{Three-Sided Game Analysis for EB Investment}

The interaction among three stakeholders (i.e., government, wind farms, and CHP plants) is analyzed in the framework of game. For simplicity, all wind farms and the CHP plants are considered to be one player. In the game model, we use Player G, Player W, and Player C to represent the government, wind farm, and CHP plant stakeholders, respectively. The social benefit of Player $\mathrm{G}-$ i.e., emissions reduction due to wind power accommodation - and the economic benefits of Player $\mathrm{W}$ and Player $\mathrm{C}$ are referred to the utilization in the game model.

The capacities of the EBs impact the utilization of the players by affecting the accommodated quantity of wind power. The three players try to maximize their utilization by adjusting their investment involvement, which determines the capacity of the EB installation. Player G provides a subsidy for EB investment. Player W provides a subsidy for EB investment and a profit concession to Player $C$ for extra wind power sales. Player $C$ invests in EB while enjoying subsidy and profit concessions from his counterparts. Thus, Player $C$ serves a main role in the investment process; the actions of the three stakeholders are dependent on the decisions of Player $\mathrm{C}$. The game flow is shown in Figure 2, and the process is detailed as follows: 

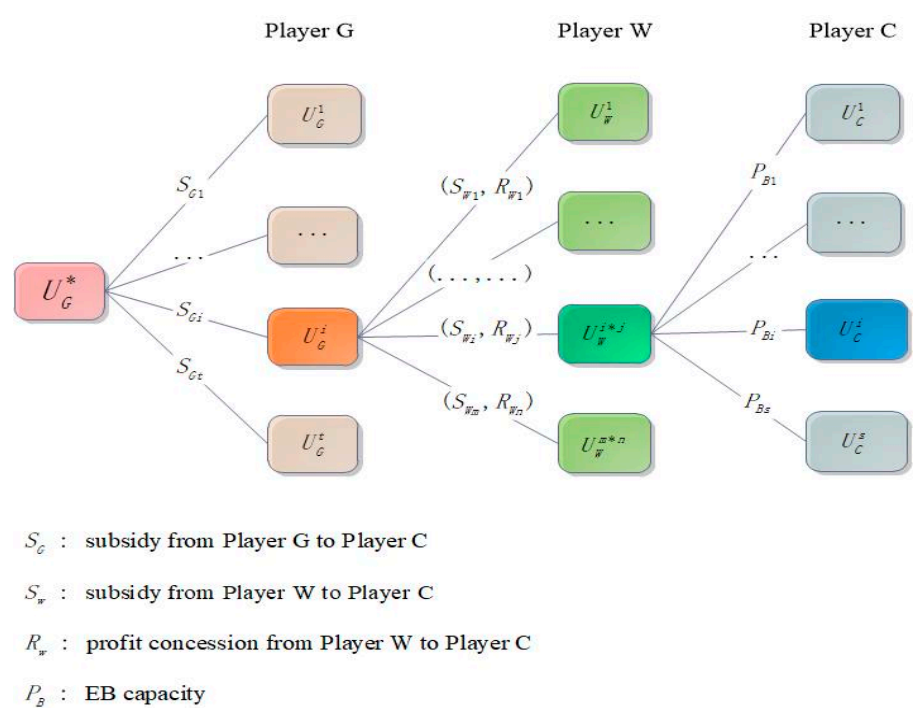

Figure 2. Game model flow process.

Step 1. Player $\mathrm{G}$ offers a set of subsidies to Player $\mathrm{C},\left\{\mathrm{S}_{\mathrm{G} 1}, \mathrm{~S}_{\mathrm{G} 2}, \ldots, \mathrm{S}_{\mathrm{G} t}\right\}$.

Step 2. Player $W$ offers a set of subsidies $\left\{S_{W 1}, S_{W 2}, \ldots, S_{W m}\right\}$ and a set of profit concessions $\left\{R_{W 1}\right.$, $\left.\mathrm{R}_{\mathrm{W} 2}, \ldots, \mathrm{R}_{\mathrm{W} n}\right\}$ to Player $\mathrm{C}$ for a certain subsidy from Player $\mathrm{G}$ to Player $\mathrm{C}$.

Step 3. Player $C$ maximizes his utilization $U_{\mathrm{C}}$ by adjusting the installed EB capacity investment $P_{\mathrm{B}}$ in every scenario of $\left\{\mathrm{S}_{\mathrm{G} i}, \mathrm{~S}_{\mathrm{W} j}, \mathrm{R}_{\mathrm{W} k}\right\}$. The dominant strategy for Player $\mathrm{C}$ for each scenario is obtained.

Step 4. Player $\mathrm{W}$ determines his optimum strategy with minimum subsidies and profit concessions to maximum his utilization by comparing all strategies of Player $C$ for every scenario.

Step 5. Player $\mathrm{G}$ determines his optimum strategy with minimum subsidies and maximum utilization by comparing all the strategies of Player $\mathrm{W}$ for every scenario.

The game model is shown in Formula (6).

$$
\begin{gathered}
z_{3}=\max \left(U_{\mathrm{G}}\right) \\
\text { s.t. }\left\{\begin{array}{c}
z_{2}=\max \left(U_{\mathrm{W}}\right) \\
\text { s.t. }\left\{\begin{array}{l}
z_{1}=\max \left(U_{\mathrm{C}}\right) \\
\text { s.t. }\left\{U_{\mathrm{C}}>0\right.
\end{array}\right.
\end{array}\right.
\end{gathered}
$$

\subsubsection{Utilization Analysis}

The annual benefits and annual amortized costs of the initial investments that were calculated using the levelized cost of energy method are employed to model the benefits of wind farms and CHP plants, following the approach proposed in [16].

The profit concession from Player $\mathrm{W}$ and the subsidies for the installed EB capacity from both Player G and Player W directly impact the EB investment from Player C; which affects their benefits from this project.

Player $\mathrm{G}$ obtains a social benefit from additional wind power accommodation while offering subsidies to Player $C$ for the capacity installation of EBs.

Player $\mathrm{W}$ provides a profit concession according to his profits from extra wind power accommodation and provides one-off subsidies to Player $C$ based on the installed EB capacity.

Installing EBs decreases Player C's power supply and production costs by decreasing Player C's heat supply. Player $\mathrm{C}$ receives a profit concession from Player $\mathrm{W}$, realizes savings from decreasing the production cost with correspondingly less output, makes less income due to the decreased sale of 
electricity, and pays for the installed EB capacity, with the exception of the subsidy proportion from the remaining two players.

Their utilizations are calculated as

$$
\begin{gathered}
U_{G}=Q \times e-P_{B} \times c_{1} \times S_{G} \\
U_{W}=Q \times p_{1} \times\left(1-R_{W}\right)-P_{B} \times c_{1} \times S_{W} \\
U_{C}=Q \times p_{1} \times R_{W}+Q / \theta \times c_{2}-Q \times p_{2}-P_{B} \times c_{1} \times\left(1-S_{G}-S_{W}\right)
\end{gathered}
$$

As game decisions are one-shot decisions, annual values are used to calculate the game results.

\subsubsection{Game Analysis for the Unit Cost of CHP Plants}

As shown in Formula (9), the accounting method of the unit cost $c_{2}$ to supply electricity in a CHP plant affects the profit of Player $\mathrm{C}$ and his utilization and action. Less profit is associated with a high unit cost when the electricity price is fixed. Player $C$ tends to declare a low cost to claim higher compensation from his counterparts, whereas Player $\mathrm{W}$ prefers to use a high cost accounting method to pay for a smaller calculated loss of Player $C$. Therefore, determining the accounting method of $c_{2}$ is a contradiction in this game.

The marginal cost and average cost are the most common measures for determining the unit production cost. The marginal cost is typically employed when profits are determined, excluding fixed asset investments, whereas the average cost is employed when profits, including fixed asset investments, are calculated [26].

All decisions and actions of the three stakeholders are dependent on the profit variation of Player C. Player $C$ prefers to calculate his profit using marginal costs, which are low cost to receive higher compensatory payment in this project. However, Player W prefers to use the average cost to measure Player C's cost to obtain an advantage when bargaining with Player $C$ for the compensatory payment. Thus, $\mathrm{c}_{2}$ will be set in the process of the game action between Player $\mathrm{W}$ and Player $\mathrm{C}$.

We introduce a payoff function, which is extensively applied in game theory to represent player utilization, to analyze how $c_{2}$ is determined. The payoff functions of Player $\mathrm{C}$ and Player $\mathrm{W}$ for the accounting of unit $\operatorname{cost} c_{2}$ are assumed to be linear [27], as represented by Line AB and Line OC shown in Figure 3.

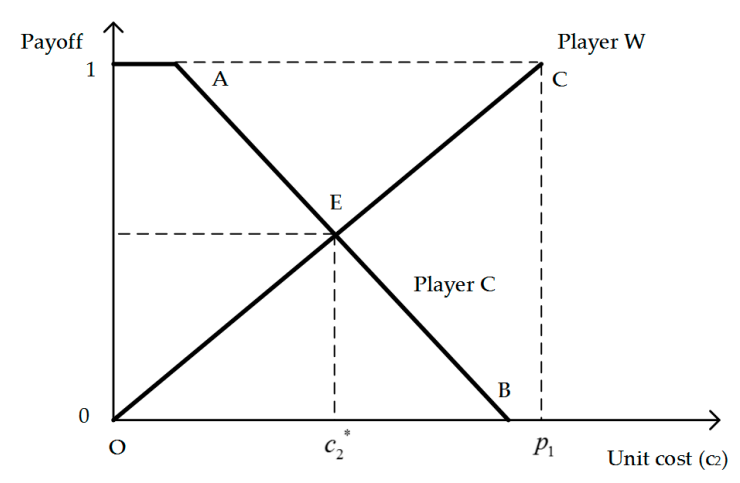

Figure 3. Payoff functions of Player W and Player C.

In Figure 3, Point A and Point B are two extreme situations of Player C's payoff: Player C has the lowest payoff at Point $B$ when the unit cost reaches its maximum value (average cost) and the highest payoff at Point $\mathrm{A}$ (marginal cost). Point $\mathrm{O}$ and Point $\mathrm{C}$ are two extreme situations of Player W's payoff function. As Player W does not know the exact unit cost of Player C, he has to speculate this cost according to information that he has obtained. He believes that the lowest unit cost is zero 
and that the highest cost is $p_{1}$, beyond which Player $C$ would buy wind power to sell rather than generate electricity.

Therefore, Point $\mathrm{E}$, which is the intersection of Line $\mathrm{AB}$ and Line $\mathrm{OC}$, is the equilibrium of the game, where the unit $\operatorname{cost} c_{2}^{*}$ of Player $C$ can be calculated as

$$
c_{2}^{*}=\frac{c_{\mathrm{B}} \times p_{1}}{c_{\mathrm{B}}+p_{1}-c_{\mathrm{A}}}
$$

where $c_{\mathrm{A}}$ and $c_{\mathrm{B}}$ are the marginal unit cost and the average unit cost, respectively, that correspond to Point A and Point B, respectively, in Figure 3.

\subsection{Approach and Tricks for Solving the Model}

Player $C$ will give an investment response of $P_{\mathrm{B}}$ to maximize his utilization for any given set of $\left(S_{\mathrm{G}}, S_{\mathrm{W}}, R_{\mathrm{W}}\right)$. Player $\mathrm{W}$ can determine his optimum tactic of $\left(S_{\mathrm{W}}, R_{\mathrm{W}},\right)$ by examining all responses of Player $C$ for the scenario of the given $S_{\mathrm{G}}$. Then, Player $\mathrm{G}$ determines his optimum $S_{\mathrm{G}}$ by examining all responses of Player $\mathrm{W}$.

A function of real wind power curtailment is a main requirement for this project; however, it is not usually available due to its irregularity. A Monte Carlo-based simulation is suggested to approximate this function. First, wind speed is obtained by Monte Carlo, following the process proposed in [16], and the theoretical wind power output is estimated using a wind speed-power relationship curve. Next, the wind power curtailment is simulated by calculating the gap between the load demand and the obligatory output of the power system.

Formula (6) is resolved by searching the optimum set of the following four variables: the subsidy ratio from Player $G$, the subsidy ratio from Player $\mathrm{W}\left(S_{\mathrm{G}}, S_{\mathrm{W}}\right)$, the profit concession $R_{\mathrm{W}}$, and the installed EB capacity $P_{\mathrm{B}}$. Obtaining an optimum solution for Formula (6) is difficult using a mathematic optimization method. Here, an approximate enumeration method is proposed for this solution. We construct a discrete space of these four variables to approximate their solution space, in which $S_{\mathrm{G}}, S_{\mathrm{W}}$, and $R_{\mathrm{W}}$ are examined from $0 \%$ to $100 \%$ with a step of $1 \%$, and $P_{\mathrm{B}}$ is examined with a step of $1 \%$ in the installed EB capacity.

\section{Case Study}

\subsection{Data Sources and Background}

The real data of the BTH power grid are employed in this paper. In 2015, the minimum electric load was approximately $37,000 \mathrm{MW}$, the installed CHP generator capacity was 25,000 MW, and the wind power curtailment ratio was $7.8 \%$. Details are provided in [16]. As additional CHP plants are reconstructed from condensing units in the incentive policy of the Chinese government, the capacity of the grid to accommodate wind power has decreased, and concerns about grid security have increased. The BTH power grid should ensure sufficient future capacity for operation security while accommodating current wind power. We received funding from the BTH power grid to determine a solution to this issue. In a previous study, we suggested exploiting EBs to increase the flexibility of $\mathrm{CHP}$ plants and concluded that the optimum capacity of the BTH grid is $1100 \mathrm{MW}$. However, who should invest in EBs, how to encourage them to invest, and how to design an investment incentive mechanism have not been discussed. This paper aims to resolve these issues.

\subsection{Effect of EBs on Wind Power Accommodation}

The average thermoelectric ratio of a typical CHP plant in BTH with a rated power of $300 \mathrm{MW}$ is calculated to be $6.67 \mathrm{GJ} / \mathrm{MWh}$. Some excellent EBs' thermoelectric conversion efficiency is nearly $100 \%$. We assume that EBs with a rated power of $30 \mathrm{MW}$ supply heat at $108 \mathrm{GJ} / \mathrm{h}$ and that $1 \mathrm{kWh}=3.6 \times 10^{6} \mathrm{~J}$. Therefore, the effectiveness of EBs for wind power accommodation $\theta$ is 1.54 according to the calculation 
from Formulas (1)-(3). This result indicates that an additional $1.54 \mathrm{kWh}$ of wind power will be accommodated for every $\mathrm{kWh}$ of electricity that is consumed by the EBs.

The additional parameter values that are employed for the calculations are listed in Table 1.

Table 1. Parameter values.

\begin{tabular}{cccc}
\hline Parameter & Meaning & Value & Units \\
\hline$e$ & Environmental emissions cost of the power sector & 0.0109 & $\mathrm{US} \$ / \mathrm{kWh}$ \\
$c_{1}$ & Annual value of EB investment cost per unit & 7253.63 & $\mathrm{US} \$ / \mathrm{kWh}$ \\
$p_{1}$ & Unit profit of wind power & 0.0740 & $\mathrm{US} \$ / \mathrm{kWh}$ \\
$p_{2}$ & Unit price of power supplied by the CHP plant & 0.0725 & $\mathrm{US} \$ / \mathrm{kWh}$ \\
$c_{2}^{\prime}$ & Average unit cost of CHP units & 0.0551 & $\mathrm{US} \$ / \mathrm{kWh}$ \\
$c_{2}^{\prime \prime}$ & Marginal unit cost of CHP units & 0.0174 & $\mathrm{US} \$ / \mathrm{kWh}$ \\
\hline
\end{tabular}

Data resource: $e$ is discussed in [28,29]; $c_{1}$ is calculated according to [16]; and the remaining data are assessed using actual data from typical plants and the grid of BTH in 2016. The parameter values are measured in the Chinese currency RMB Yuan and are converted to US dollars in the analysis at the rate of 1 US $\$=6.8931$ Yuan, comparing the U.S. dollar against the RMB exchange rate.

\subsection{Game Results}

Using the approach presented in Section 2.3 to solve the model with the previously mentioned parameters, we computed it in MATLAB and obtained all game outcomes for different government subsidy scenarios. The government can identify the best subsidy option by comparing these outcomes. The game results can be described as follows: the equilibrium results of the game are listed in Table 2 based on the annual value calculation.

Table 2. Main results.

\begin{tabular}{cccc}
\hline Item & Government & Wind Farms & CHP Plants \\
\hline Subsidies (US \$/MW) & 1305.65 & 5802.90 & -7108.56 \\
Profit concession (US \$/kWh) & - & 0.0599 & -0.0205 \\
Investment (MW) & - & - & 1110 \\
Benefits (US \$) & $4.95 \times 10^{6}$ & $1.93 \times 10^{6}$ & $4.58 \times 10^{4}$ \\
Return on investment (\%) & 341.34 & 29.93 & 28.50 \\
\hline
\end{tabular}

Among the total 7253.63 US \$/MW annual investment, all EB capacity investment from the CHP plant is only 145.07 US \$/MW with the 7108.56 US \$/MW of subsidies from government and wind farms.

The subsidies provided by the government to the CHP plants for the installed EB capacity is 1305.65 US \$/MW, where the social benefit reaches its peak value, as shown in Figure 4.

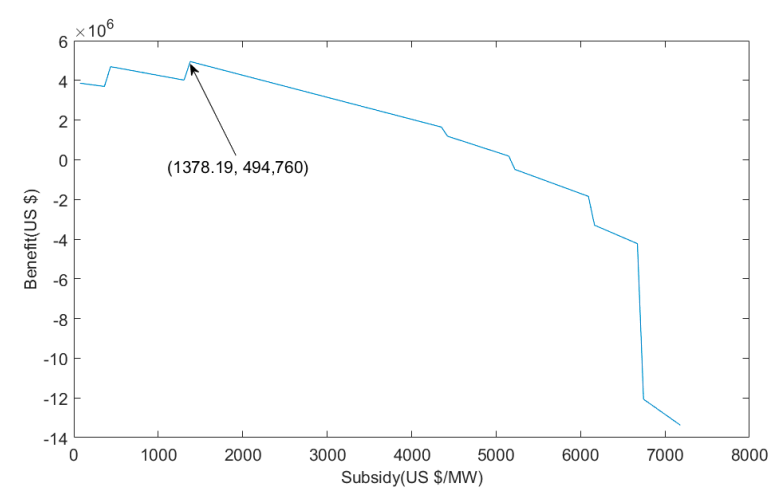

Figure 4. Benefits of government. 
The subsidy from wind farms to CHP plants for the installed EB capacity is 5802.90 US $\$ / M W$, and the profit concession based on the quantity of accommodated wind power is $0.0599 \mathrm{US} \$ / \mathrm{kWh}$ for the scenario with government subsidies of 1305.65 US \$/MW, as shown in Figure 5.

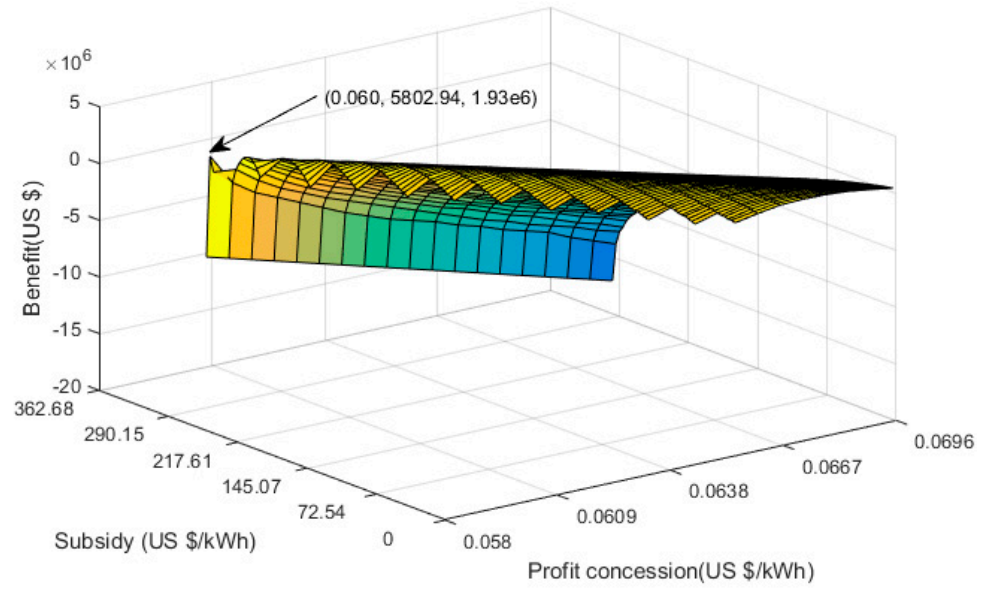

Figure 5. Benefits of wind farms.

Figure 6 shows the benefits of CHP plants with government subsidies of 1305.65 US \$/MW, wind farm subsidies of 5802.90 US $\$ / \mathrm{MW}$, and wind farm profit concessions of $0.0599 \mathrm{US} \$ / \mathrm{kWh}$. This figure indicates that the optimum installed EB capacity for the CHP plants is $1110 \mathrm{MW}$, which is similar to the capacity of $1100 \mathrm{MW}$ suggested in [16], which validates the proposed model.

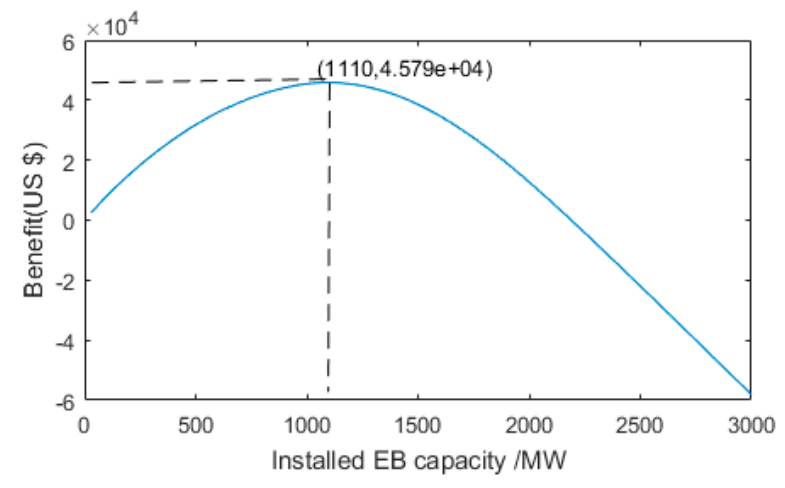

Figure 6. Benefits of CHP plants with varying installed EB capacity.

Installing $1110 \mathrm{MW}$ of EBs will reduce the CHP output by $10 \%$ in the valley load period, which will increase the peak regulation margin by $1400 \mathrm{MW}$. The optimum installed EB capacity will be implemented by CHP plants with the minimum government subsidy.

\section{Conclusions}

This paper investigated the government subsidy mechanism for promoting EBs to accommodate wind power. This study developed a game model to simulate the decision process of the involved parties and calculated the minimum government subsidy that would maximize social benefits while maximizing the benefits of both wind farms and CHP plants. An approximate enumeration technique to analyze the effect of the EB investment on both wind farms and CHP plants was employed to determine their optimum actions. A case study was conducted using the data of the BTH grid in 2015.

The results of the game model indicated that if the government provides an annual subsidy of 1305.65 US \$/MW to the CHP plants for the EB investment, then the optimum installed EB capacity of $1110 \mathrm{MW}$ will be achieved. 
Some improvements could be achieved in future studies. This paper attempted to make a decision from the government perspective, assuming that CHP plants will accept any profitable proposal. However, the CHP plant may desire profits beyond those proposed in this model as they have considerable influence on this investment decision. Furthermore, wind farms can participate in this project and act individually rather than being regarded as a single player; the same notion is valid for CHP plants. Therefore, the actual game analysis will be substantially more complex.

Acknowledgments: This study is supported by the Major Program of the National Social Science Fund of China via Grant No. 15ZDB165, the National Science and Technology Support Project of China via Grant No. 2015BAA01B01, and the Hebei Province Social Science Fund Project via Grant No. HB16GL063.

Author Contributions: Da Liu and Shoukai Wang conceived and designed the experiments; Shoukai Wang and Jinchen Liu performed the experiments; Da Liu and Yi Feng analyzed the data; Shoukai Wang and Han Huang wrote the paper; Da Liu and Jinchen Liu finalized the manuscript in discussion with Xingping Zhang and Weijun Wang.

Conflicts of Interest: The authors declare no conflict of interest.

\section{Nomenclature}

$\begin{array}{ll}\text { BTH } & \text { Beijing-Tianjin-Hebei } \\ \text { CHP } & \text { Combined heat and power } \\ \text { EBs } & \text { Electric boilers } \\ \text { Player C } & \text { CHP plants } \\ \text { Player G } & \text { Government } \\ \text { Player W } & \text { Wind farms }\end{array}$

\section{Symbols}

$\mathrm{c}_{1} \quad$ Unit cost of the EB investment

$\mathrm{c}_{2} \quad$ Unit cost of Player C's electricity power production

$\mathrm{c}_{2} \prime \quad$ Unit cost of CHP units

$\mathrm{c}_{2}{ }^{\prime \prime} \quad$ Marginal unit cost of CHP units

$c_{2}^{*} \quad$ Unit cost

$\mathrm{c}_{\mathrm{A}} \quad$ Marginal unit cost

$\mathrm{C}_{\mathrm{B}} \quad$ Average unit cost

e Unit environmental emissions cost of the power sector

E Electric power generated by CHP units before employing EBs

$\mathrm{H} \quad$ Heat generated by CHP units before employing EBs

kW Kilowatt

MW Megawatt

$p_{1} \quad$ Unit profit of Player $\mathrm{W}$ gained from this project

$p_{2} \quad$ Unit cost of supplying electricity for Player C

$P_{B} \quad$ Capacity of EBs to be invested

$P_{w_{t}} \quad$ Wind power curtailment at time of $t$

Q Quantity of wind power accommodation after employing EBs

$R_{W} \quad$ Profit concession from Player $\mathrm{W}$ to Player $\mathrm{C}$

$S_{G} \quad$ Subsidy from Player $\mathrm{G}$ to Player $\mathrm{C}$

$S_{W} \quad$ Subsidy from Player $\mathrm{W}$ to Player $\mathrm{C}$

$t \quad$ Time of $t$

$U_{C} \quad$ Utilization of Player $\mathrm{C}$

$U_{G} \quad$ Utilization of Player $\mathrm{G}$

$U_{W} \quad$ Utilization of Player $\mathrm{W}$

$v \quad$ Dummy variable that indicates whether this project can complete prevent wind power curtailment

$\Delta t \quad$ Duration of each time segment 


\section{References}

1. Lewis, J.I.; Fridley, D.G.; Price, L.K.; Lu, H.; Romankiewicz, J.P. Understanding China's non-fossil energy targets. Science 2015, 350, 1034-1036. [CrossRef] [PubMed]

2. Fan, X.C.; Wang, W.Q.; Shi, R.J.; Li, F.T. Analysis and countermeasures of wind power curtailment in China. Renew. Sustain. Energy Rev. 2015, 52, 1429-1436. [CrossRef]

3. Kang, J.; Yuan, J.; Hu, Z.; Xu, Y. Review on wind power development and relevant policies in China during the 11th five-year-Plan period. Renew. Sustain. Energy Rev. 2012, 16, 1907-1915. [CrossRef]

4. Chen, X.; Kang, C.; O'Malley, M.; Xia, Q.; Bai, J.; Liu, C.; Sun, R.; Wang, W.; Li, H. Increasing the flexibility of combined heat and power for wind power integration in China: Modeling and implications. IEEE Trans. Power Syst. 2015, 30, 1848-1857. [CrossRef]

5. Kuhi-Thalfeldt, R.; Valtin, J. Combined heat and power plants balancing wind power. Oil Shale 2009, 26, 294-308. [CrossRef]

6. Georgilakis, P.S. Technical challenges associated with the integration of wind power into power systems. Renew. Sustain. Energy Rev. 2008, 12, 852-863. [CrossRef]

7. Mathiesen, B.V.; Lund, H. Comparative analyses of seven technologies to facilitate the integration of fluctuating renewable energy sources. IET Renew. Power Gener. 2009, 3, 190-204. [CrossRef]

8. Luo, G.L.; Li, Y.L.; Tang, W.J.; Wei, X. Wind curtailment of Chin's wind power operation: Evolution, causes and solutions. Renew. Sustain. Energy Rev. 2016, 53, 1190-1201. [CrossRef]

9. Kapsali, M.; Kaldellis, J.K. Combining hydro and variable wind power generation by means of pumped-storage under economically viable terms. Appl. Energy 2010, 87, 3475-3485. [CrossRef]

10. Vargas, L.S.; Bustos-Turu, G.; Larrain, F. Wind power curtailment and energy storage in transmission congestion management considering power plants ramp rates. IEEE Trans. Power Syst. 2014, 30, 2498-2506. [CrossRef]

11. Atwa, Y.M.; El-Saadany, E.F. Optimal allocation of ESS in distribution systems with a high penetration of wind energy. IEEE Trans. Power Syst. 2010, 25, 1815-1822. [CrossRef]

12. Saebi, J.; Javidi, M.H. Economic evaluation of demand response in power systems with high wind power penetration. J. Renew. Sustain. Energy 2014, 6, 627-632. [CrossRef]

13. Khazali, A.; Kalantar, M. Optimal generation dispatch incorporating wind power and responsive loads: A chance-constrained framework. J. Renew. Sustain. Energy 2015, 7, 1319-1348. [CrossRef]

14. Tan, Z.; Chen, K.; Ju, L.; Liu, P.; Zhang, C. Issues and solutions of China's generation resource utilization based on sustainable development. J. Mod. Power Syst. Clean Energy 2016, 4, 147-160. [CrossRef]

15. Song, Y.H.; Zhang, C.; Tan, Z.F.; Shi, Q. Interregional electric power planning model based on sustainable development of wind power. J. Energy Eng. 2015, 141, 1-10. [CrossRef]

16. Liu, D.; Zhang, G.; Huang, B.; Liu, W. Optimum electric boiler capacity configuration in a regional power grid for a wind power accommodation scenario. Energies 2016, 9, 144. [CrossRef]

17. Zhang, N.; Lu, X.; Mcelroy, M.B.; Nielsen, C.P.; Chen, X.; Deng, Y.; Kang, C. Reducing curtailment of wind electricity in China by employing electric boilers for heat and pumped hydro for energy storage. Appl. Energy 2016, 184, 987-994. [CrossRef]

18. Quan, L.; Hao, J.; Chen, T.; Wang, H.; Yang, L.; Weidong, L.I. Wind power accommodation by combined heat and power plant with electric boiler and its national economic evaluation, automation of electric. Power Syst. 2014, 38, 6-12.

19. Nielsen, M.G.; Morales, J.M.; Zugno, M.; Pedersen, T.E.; Madsen, H. Economic valuation of heat pumps and electric boilers in the Danish energy system. Appl. Energy 2016, 167, 189-200. [CrossRef]

20. Meibom, P.; Kiviluoma, J.; Barth, R.; Brand, H.; Weber, C.; Larsen, H.V. Value of electric heat boilers and heat pumps for wind power integration. Wind Energy 2007, 10, 321-337. [CrossRef]

21. Jiajia, L.I.; Linxian, H.U. Research on accommodation scheme of curtailed wind power based on peak-shaving electric boiler in secondary heat supply network. Power Syst. Technol. 2015, 39, 3286-3291.

22. Jiang, X.S.; Jing, Z.X.; Wu, Q.H.; Ji, T.Y. Modeling of a central heating electric boiler integrated with a stand-alone wind generator. In Proceedings of the 2013 IEEE PES Asia-Pacific Power and Energy Engineering Conference (APPEEC), Kowloon, Hong Kong, China, 8-11 December 2013; pp. 1-6.

23. Bai, C.; Sarkis, J. Supplier development investment strategies: A game theoretic evaluation. Ann. Oper. Res. 2016, 240, 583-615. [CrossRef] 
24. Chang, P.L.; Ho, S.P.; Hsu, C.W. Dynamic simulation of government subsidy policy effects on solar water heaters installation in Taiwan. Renew. Sustain. Energy Rev. 2013, 20, 385-396. [CrossRef]

25. Chou, S.Y.; Nguyen, T.A.T.; Yu, T.H.K.; Phan, N.P. Financial assessment of government subsidy policy on photovoltaic systems for industrial users: A case study in Taiwan. Energy Policy 2015, 87, 505-516. [CrossRef]

26. Stinespring, J.R. Fixed versus sunk costs: Creating a consistent and simplified cost framework. J. Econ. Econ. Educ. Res. 2011, 12, 11-26.

27. Dilme, F. Cooperation in Large Societies, 2nd ed.; PIER Working Paper 14-021; Social Science Research Network: New York, NY, USA, 1 June 2014.

28. Liu, Z.; Ye, X. Study on the external environment cost of coal power generation based on the emission factor method. Electr. Power Sci. Eng. 2014, 30, 63-69.

29. Huang, L.; Hu, J.; Chen, M.; Zhang, H. Impacts of power generation on air quality in China-part I: An overview. Resour. Conserv. Recycl. 2016, 121, 103-114. [CrossRef]

(C) 2017 by the authors. Licensee MDPI, Basel, Switzerland. This article is an open access article distributed under the terms and conditions of the Creative Commons Attribution (CC BY) license (http://creativecommons.org/licenses/by/4.0/). 